\title{
Kuvia metsäkansan luontosuhteista
}

Ate Tervonen 
lin jo vuosia kerännyt satunnaisesti metsistä löytämiäni roskia. Syyskuussa 2019 aloin kantaa päivittäisillä retkillä mukanani pusseja ja kerätä roskia järjestelmällisesti. Pussit täyttyivät nopeasti tupakantumpeista, käärepapereista, juomatölkeistä, shampoopulloista, miesten boksereista sekä kaikesta muusta ilmeisestä ja yllättävästä. Samalla aloin dokumentoida ihmisten jälkiä ja ihmisluontoa metsissä valokuvaamalla ja jakamaan kuvia projektia varten perustamallani Instagram-tilillä - luontokuvia, joita kenenkään ei pitäisi haluta nähdä.

Suomalaisen metsäkansan kiinnostus luontoa kohtaan näkyy Instagramin kuvavirrassa huikaisevina valokuvina, joissa horisonttiin jatkuvat tunturinhuiput hohtavat laskevan auringon valossa, sumu leijuu uuteen päivään heräävässä aarniometsässä tai revontulet loistavat uskomattoman värikylläisinä.

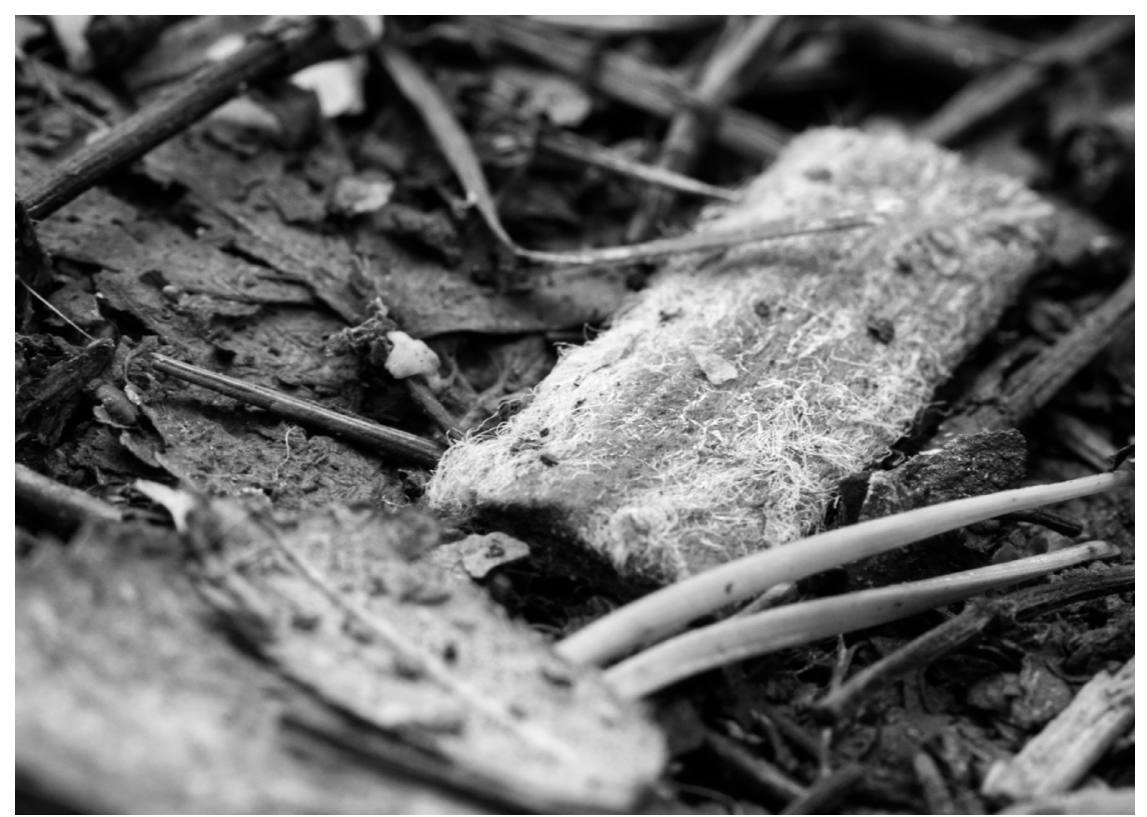

Puista ja ihmisistä pudonneita

Instagramin luontokuvatilit näyttäisivät kasvattaneen viime vuosina suosiotaan yhtä aikaa retkeilyharrastuksen kanssa. Suositut luontokuvatilit kertovat, mikä ihmisiä usein kiinnostaa luonnossa: esteettiset erämaamaisemat ja eläimet, jotka ovat söpöjä tai inhimillistettyjä. Jos kuvissa näkyy merkkejä ihmisistä, kyse on usein tilinomistajasta itsestään retkeilemässä jylhissä maisemissa tai romanttisesta metsäpirtistä kuusten varjossa. Näin luontokuva uusintaa romanttista käsitystä ihmisestä erillisestä ja itseään korjaavasta luonnosta ja erämaista, jotka ovat ihmisvaikutuksen ulkopuolella. Ympäristökriisiä kuvat eivät tavoita. 


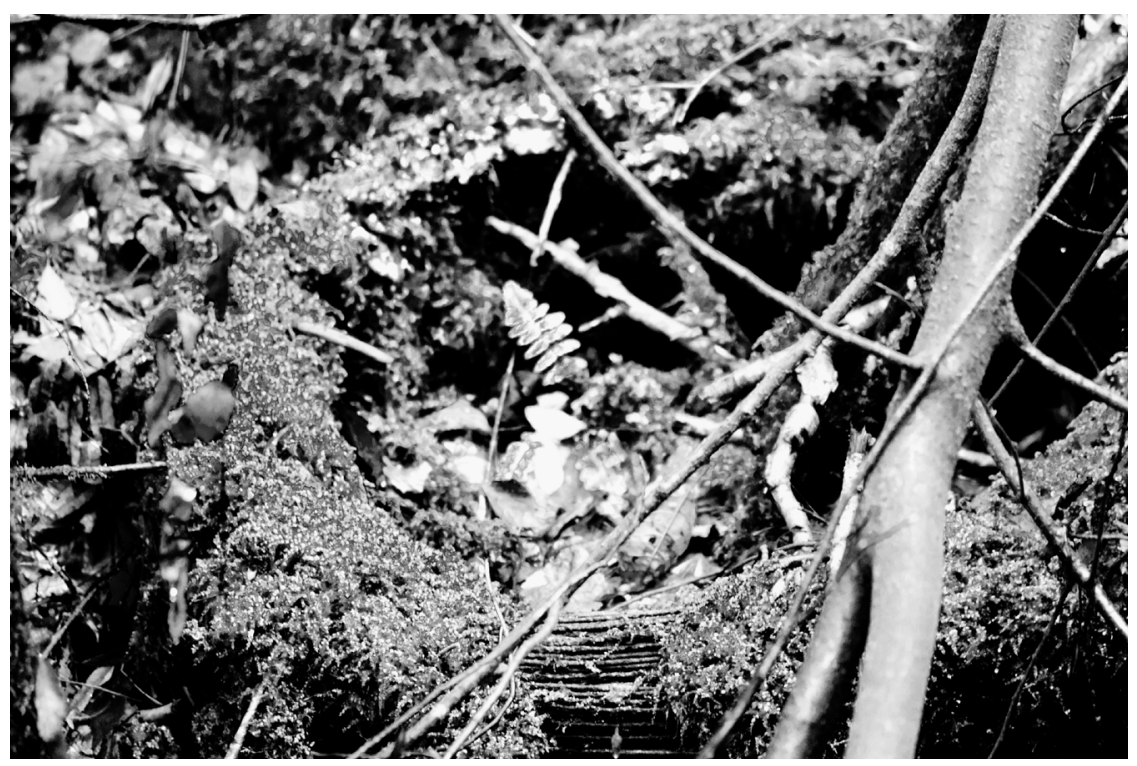

Sammal on vallannut ruostuneen rautalankavyyhdin kasvualustakseen

Se, miten ihmiset vaikuttavat luontoon ympärillään ja millaisia jälkiä he jättävät ympäristöön, rajataan yleensä Instagramin luontokuvien ulkopuolelle. Teleliikennemastot, sähkölinjat, tiheä talousmetsätaimikko, puista ja useimmista eläimistä tyhjennetyt avohakkuut ja metsien roskaisuus eivät päädy kuviin.

Kuvissa korostuu ihmisestä vapaa erämaa - Yhdysvalloista peräisin olevan modernin luonnonsuojeluaatteen ihanne. Erämaiden koskemattomuus on kuitenkin näennäistä, sillä ihmiset ovat asuneet niissä tuhansia vuosia ja vaikuttaneet väistämättä ympäristöönsä (ks. Haila 2003). Nykyisin retkeilyturismi, ylimitoitettu porotalous ja ilmastonmuutos vaikuttavat syrjäisimpiinkin alueisiin, mutta nostalginen ajatus villistä erämaasta ja sen tunturinhuippujen valloittajasta elää edelleen Instagramin luontokuvastoissa. Ajatus valloitettavista erämaista on aiheuttanut myös sen, että luontoon on alettu suhtautua toisena ja ulkopuolisena. Suomessa karelianistien romanttiset luontokuvaukset ovat tuoneet tähän ajatteluun oman nationalistisen lisänsä. (Haila 2003, 178-179.)

Kuvissa elää edelleen voimakas dikotomia luonnon ja kulttuurin välillä. Kirjallisuudentutkija Timothy Morton (2007 \& 2016) onkin tarkastellut ajatusta kulttuurin ja luonnon erkaantumisesta maanviljelyn syntyessä Mesopotamiassa 12000 vuotta sitten ja todennut, että käsitystä jylhästä ja itseään korjaavasta kulttuurin ulkopuolisesta luonnosta on tarvittu oikeuttamaan pyrkimykset voittaa ja valjastaa luonto. Tästä ajatuksesta on ilmastonmuutoksen ja luonnon monimuotoisuuden hupenemisen myötä tullut hengenvaarallinen, mutta 
Instagramin luontokuvat leijuvat kuvausdronen tavoin irrallaan metsämaasta ja sen muutoksesta.

Ajanvietto luonnossa ja luontokuvaus voivat auttaa kehittämään ihmisten luontosuhteita nykyistä kestävämmiksi sekä paremmin toisia lajeja ja ekosysteemejä huomioiviksi. Tämä ei kuitenkaan ole yksiselitteistä, sillä retkeilijät jättävät usein jälkeensä myös roskia ja kuluttavat maastoa. Lisäksi varomaton luontokuvaus voi häiritä lintujen pesintöjä, ja Kuhmon maksullisten haaskakuvauspaikkojen tiedetään houkutelleen alueelle poikkeuksellisen paljon suurpetoja (ks. Puusa 2019). Asiaan vaikuttaa voimakkaasti se, miten luonnossa olemiseen on virittäydytty: millaisia motiiveja luonnossa liikkumiseen on, miten luontoon asennoidutaan ja millaisia kokemuksia ja tietoa luonnosta on. Myös sillä on merkitystä, miten avoimia ollaan huomaamaan ja kohtaamaan luonnossa vastaan tulevia eliöitä, asioita ja ilmiöitä. Se, mitä jätämme jälkeemme - tai olemme jättämättä, kertoo paljon luontosuhteistamme.

Luonto ei ole yksi, vaan tulee vastaan moninaisena (ks. Lehtonen 2014, 23): mustikoina valoisassa talousmännikössä, sutena, joka tappaa metsästyskoiran,

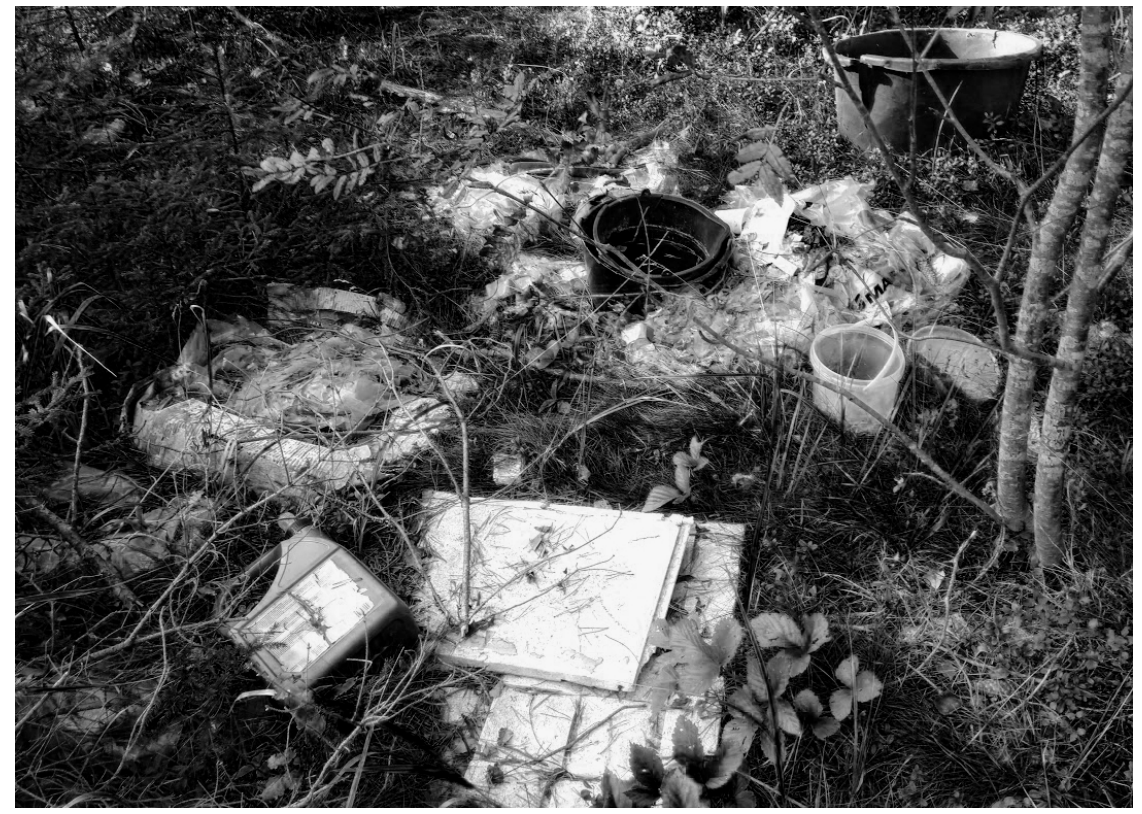

Laiton kaatopaikka metsänreunassa

erämaamaisemina, Suomeen istutetun valkohäntäpeuran levittäminä punkkeina ja vanhoina puina, jotka voi nähdä esimerkiksi osana metsää ja tarpeellisina lukuisille lintu-, sieni-, sammal- ja hyönteislajeille tai talousmetsätermein yli-ikäisenä ja korjuukypsänä. Myös ihminen on luontoa, ja ihmisillä on oma olemuksellinen luontonsa.

Luontokuvat voivat kiinnittää huomiomme siihen, mikä luonnossa on biosentrisesti arvokasta ja mikä on harvinaista ja vaarassa kadota. Kun Instagram- 


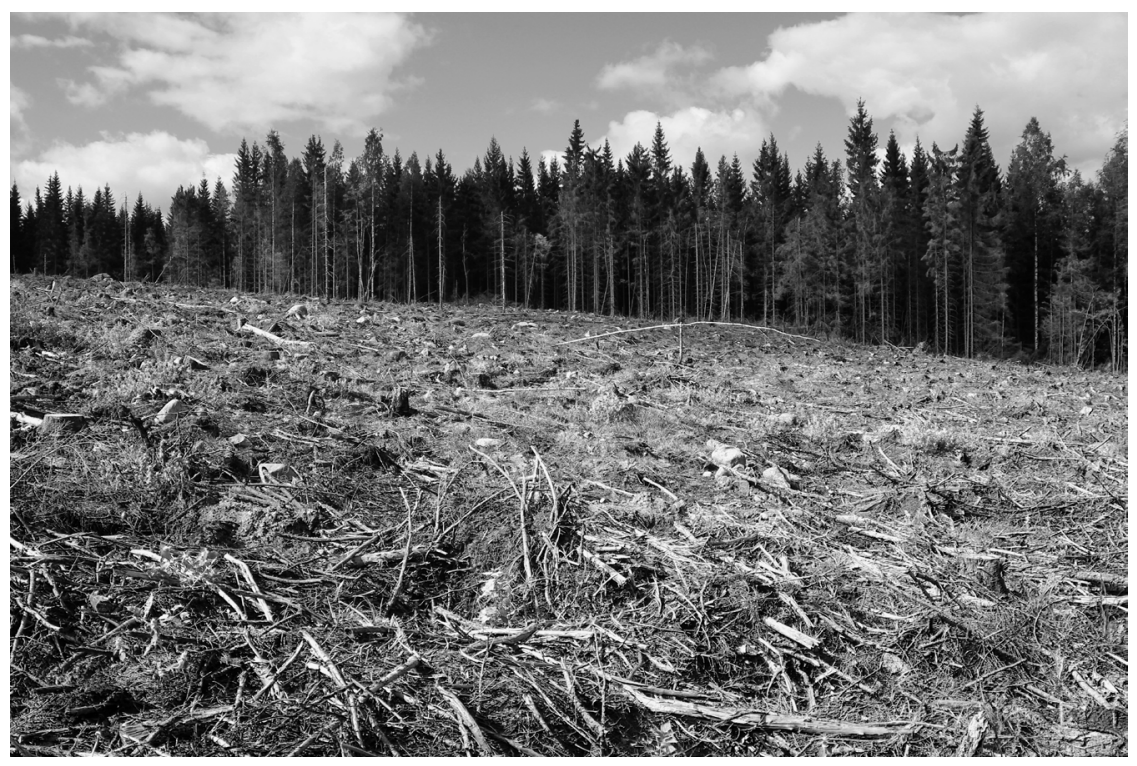

"Päätehakkuu"

kuvassa näkyy tunturinjuurelta horisonttiin yltävä yhtenäinen Lapin aarniometsä, kuva kuitenkin jää yleensä vaille kontekstia ja ymmärrystä siitä, miten harvinainen näky on Suomessa tänä päivänä. Eri arvioiden mukaan vain 1-2,9 prosenttia metsistämme on luonnontilaisia, ja varsinkin Etelä-Suomesta luonnontilainen metsä on lähes kadonnut (Forest Europe 2015 \& Sabatini et al. 2018).

\section{III}

Keräämäni roskat kertovat monenlaisista tavoista ja syistä viettää aikaa metsässä ja niistä hahmottuu erilaisia suhteita luontoon. Lähellä asutusta metsät ovat roskaisimpia, ja tupakantumppeja sekä energiajuoma- että maitokahvitölkkejä saa kerätä usein - jälkimmäisiä löytyy lähimetsästäni jatkuvasti lähes samasta paikasta. Kauempana asutuksesta roskat vähenevät selvästi ja niiden luonne muuttuu. Keskeltä metsää olen löytänyt ainakin metsureiden harvennuspaikalle jättämiä bensakanistereita, moottoripyörän piikkirenkaan ja retkikeittimen spriipulloja.

Lähimetsät ovat muita metsiä roskaisempia, mutta asutuksen läheisyys voi myös suojella metsää. Esimerkiksi Jyväskylän Laajavuoressa painottuvat suojelu- ja virkistysarvot, kun kauempana taajamasta metsä on vahvemmin talouskäytössä. Toisaalta virkistys- ja suojeluarvojen välillä on jonkin verran ristiriitaisuutta, sillä virkistysmetsistä hakataan vanhempaa puustoa ja vaarallisina pidettyjä puita. (Jyväskylän kaupunki 2020.) Vaikka luontoarvot korostuvat jossain määrin paremmin lähimetsissä kuin maaseudun talousmetsissä, on kuitenkin huomattava, että merkittävä osa suojelualueiden metsistä ja muusta 
vanhasta metsästä on säilynyt nimenomaan syrjäisyyden ja vaikeakulkuisuuden vuoksi (Keto-Tokoi \& Kuuluvainen 2010, 186-223).

Roskissa on myös selviä ajallisia kerrostumia: sateet, eroosio, tuuli ja muut luonnonilmiöt paljastavat jatkuvasti lehtien alta ja maasta roskia, joita en ole aiemmin huomannut. Erään talonraunion läheltä olen löytänyt emalivadin, rautalankavyyhdin ja lukuisia peltitölkkejä, sekä vanhoja maahan haudattuja

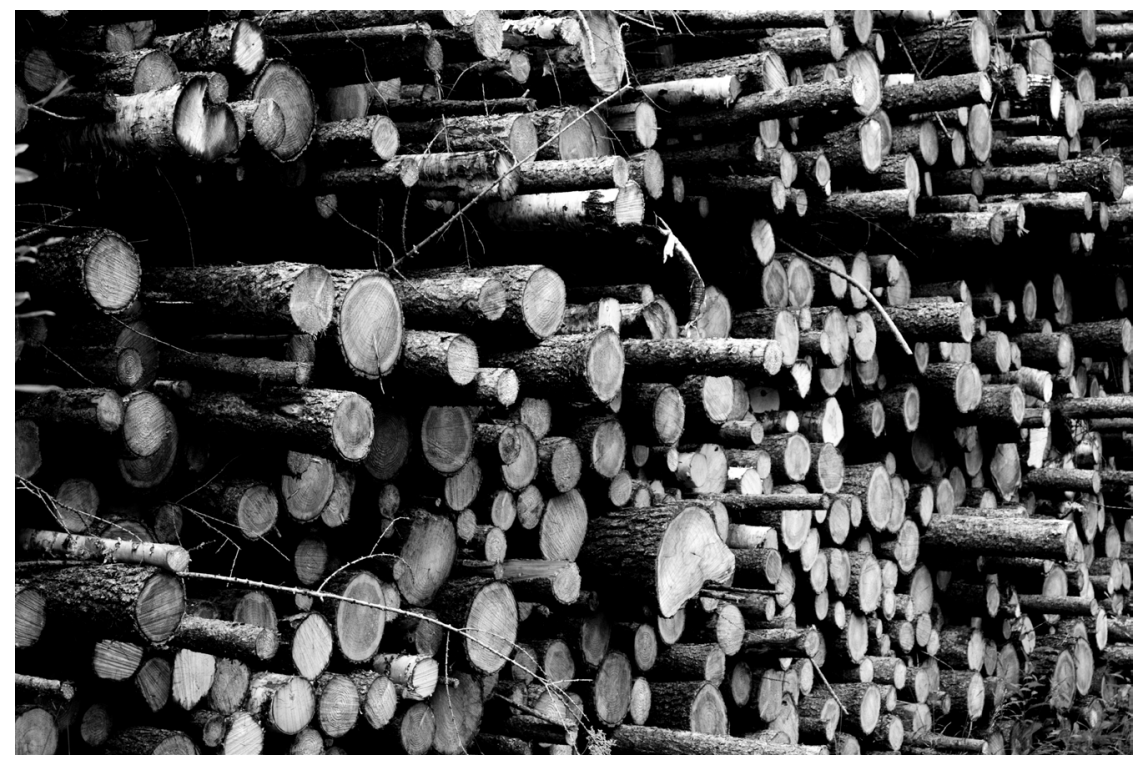

Osa metsää pinottuna

tunkioita. Metsissä - tai oikeastaan niiden laidoilla - kulkeva ei voi olla törmäämättä myös laittomiin kaatopaikkoihin, joissa lojuu rakennusjätettä, huonekaluja tai kodinkoneita.

Roskat ovat näkyvä ongelma, mutta paljon isompi uhka metsäluonnolle on tehometsätalous. Sen seurauksena kaksi kolmasosaa Suomen metsien luontotyypeistä on uhanalaisia, ja 733 metsien lajia on uhanalaistunut (Hyvärinen et al. 2019). Ihmistoiminnan rajaaminen ja lajien, populaatioiden ja ekosysteemien varjeleminen suojelualuein on tärkeää. Olennaista on kuitenkin myös se, mitä tapahtuu suojelualueiden ulkopuolella ja miten kestävästi talouskäytössä olevia metsiä hoidetaan (ks. Eyvindson et al 2020). Viime aikoina olen roskien sijaan huomannut yhä useammin kuvaavani tehotuotannon jälkiä metsissä.

Metsäluonnon hyödyntäminen ei sinänsä ole ongelma, vaan sen mittakaava, intensiteetti ja jotkin muodoista, kuten esimerkiksi laajat avohakkuut. Metsän luontokeskeisemmät merkitykset ovat yksityisen metsänomistuksen, 


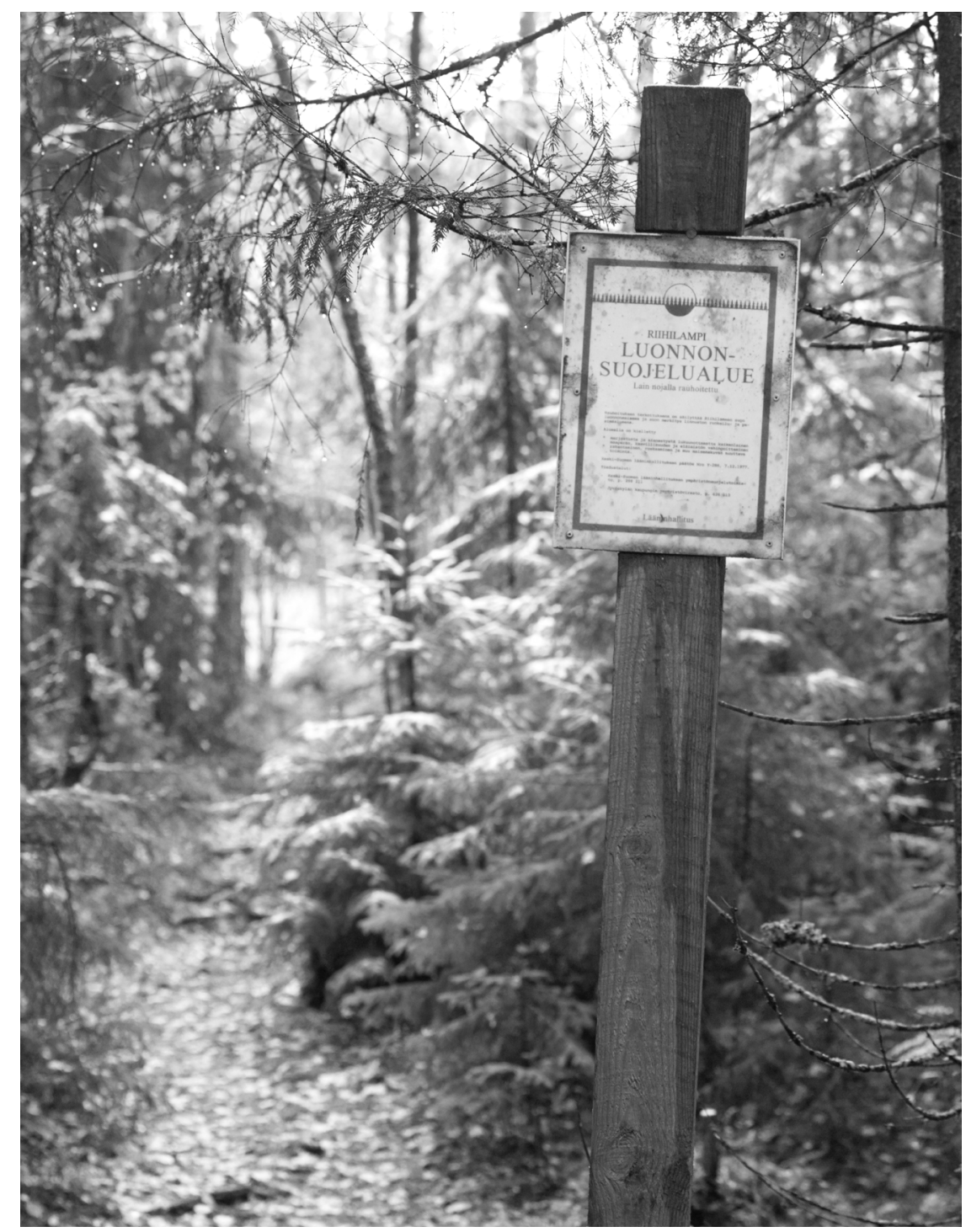

Riihilammen luonnonsuojelualue, 2,2 ha

metsäyhdistysten, Metsähallitus Metsätalous Oy:n, puutavara- ja selluyhtiöiden, työpaikkojen ja kansantalouden puristuksessa ja suojelualueet ovat liian pieniä ja etäällä toisistaan suojellakseen uhanalaisia lajeja tehokkaasti. Talousargumenttien rinnalle (uskallanko sanoa: sijaan) tarvitsisimme nöyryyttä ja ymmärrystä siitä, että tietomme luonnosta, sen monimutkaisista prosesseista ja toimiemme seurauksista ovat rajallisia ja että monet vaikutuksistamme ovat hyvin pitkäaikaisia tai peruuttamattomia.

Roskat on helppo kerätä pois, mutta hakkuuaukkoja ei voi pyyhkiä maisemasta. Emme kuitenkaan voi olla käyttämättä muita lajeja hyödyksemme. Tämänkin esseen paperiversio on painettu puuruumille. Ihmiset ovat osa 
luonnon muuttuvaa moninaisuutta (Haila \& Levins 1992, 21-22), mutta tietoisina toimijoina meillä on kuitenkin mahdollisuus ohjata muutosta nykyistä kestävämpään ja muut lajit ja ekologian huomioivaan suuntaan.

\section{V}

Kuvausprojektissani olen halunnut kiinnittää huomiota luonnolle haitallisten ihmistoimien lisäksi niihin lajimme vaikutuksiin, jotka ovat kestäviä ja tukevat luonnon jatkuvuutta. Näitä ovat esimerkiksi niinkin erisuuruiset asiat kuin linnunpöntöt, jättipalsamin kitkemiseen tähtäävä lammaslaidunprojekti ja luonnonsuojelualueet - myös kuvat jylhistä Lapin kansallispuistojen näkymistä, joiden harvinaisuutta ja luonnonsuojelullista merkitystä olen pyrkinyt avaamaan Instagramissa kuvateksteissä. Nämä kuvat kertovat metsän arvosta muunakin kuin puukuutioina - ja siitä, että luonto vaikuttaa meihin.

Kirjoittaja valmistelee kirjallisuustieteellistä väitöskirjaa Jyväskylän yliopistossa.

@jalkialuonnossa https://www.instagram.com/jalkialuonnossa/

https://luonnonjalkia.wordpress.com/

\section{Kirjallisuus}

Eyvindson, Kyle, Duflot, Rémi, Triviño, María, Blattert, Clemes, Potterf, Mária, \& Mönkkönen, Mikko 2020. High boreal forest multifunctionality requires continuous cover forestry as a dominant management. Land use Policy, 100. https://doi.org/10.1016/j.landusepol.2020.104918.

Forest Europe 2015. State of Europe's Forests 2015. Madrid: Forest Europe. https://www.foresteurope. org/docs/fullsoef2015.pdf (luettu 24.8.2020).

Haila, Yrjö 2003. 'Erämaa' ja ympäristöajattelun moniulotteisuus. Teoksessa Luonnon politiikka. Toim. Yrjö Haila \& Ville Lähde. Tampere: Vastapaino, 174-204.

Haila, Yrjö \& Levins, Richard 1992. Ekologian ulottuvuudet. Tampere: Vastapaino.

Hyvärinen, Esko; Juslén, Aino; Kemppainen, Eija; Uddström, Annika; Liukko, Ulla-Maija 2019. Suomen lajien uhanalaisuus - Punainen kirja 2019. Helsinki: Ympäristöministeriö \& Suomen ympäristökeskus.

Jyväskylän kaupunki 2020: Jyväskylän metsien hoitosuunnitelma 2020-2030. https://www.jyvaskyla. fi/sites/default/files/atoms/files/laajavuoren_hoitosuunnitelma.pdf(luettu 21.8.2020).

Keto-Tokoi, Petri \& Kuuluvainen, Timo 2010. Suomalainen aarniometsä. Helsinki: Maahenki.

Lehtonen, Mikko 2014. Maa-ilma. Tampere: Vastapaino.

Morton, Timothy 2007. Ecology without Nature. Rethinking Environmental Aesthetics. Cambridge, Mass: Harvard University Press.

Morton, Timothy 2016. Dark Ecology. For a Logic of Future Coexistence. New York: Columbia University Press.

Sabatini, Francesco Maria, Burrascano, Sabina, Keeton, William S. et al. 2018. Where are Europe's last primary forests? Divers Distrib. 24: 1426-1439. https://doi.org/10.1111/ddi.12778. 